\title{
Símbolo e Signo: O Dinheiro no Capitalismo Contemporâneo ${ }^{\star}$
}

\author{
- Leda Maria Paulani* - Leonardo André Paes Müller**
}

\begin{abstract}
Resumo
O presente texto busca refletir sobre a natureza do dinheiro no capitalismo contemporâneo, debruçandose particularmente sobre o fato de que, atualmente, não só no plano nacional, mas também no mundial, o objeto que corporifica o dinheiro é inconversível, ou seja, não tem lastro, nem nenhuma relação, por remota que seja, com uma mercadoria de verdade. O enfoque teórico é aquele oferecido pela teoria de Marx, paradigma esse que é tratado a partir de uma leitura hegeliana. Partimos da diferença entre símbolo e signo, para mostrar de que maneira Marx, movendo-se no arcabouço hegeliano, pôde construir uma linguagem das mercadorias, onde o dinheiro - e a autonomia que ele detém ante as coisas que representa - tem papel de destaque, associando, finalmente, essa construção teórica com a natureza do dinheiro no capitalismo contemporâneo.
\end{abstract}

\section{Palavras-Chave}

símbolo, signo, dinheiro, teoria monetária de Marx, capitalismo contemporâneo

\begin{abstract}
This paper aims to reflect about money in contemporary capitalism, particularly about the question related to the fact that, nowadays, even in the world level, the thing that embodies money (the American dollar) is inconvertible, i.e., doesn't have ballast, doesn't have any relationship, even remote, with a true commodity. The theoretical approach is that offered by Marxian monetary theory, paradigm that is read in a Hegelian way. We depart from the difference between symbol and sign to show how Marx, moving within the Hegelian framework, could construct a commodities language, in which money - and the autonomy it has in face of the things it represents - has a detached role. Finally we indicate the relation we see between this theoretical construct and the nature of money in contemporary capitalism.
\end{abstract}

\section{Keywords}

symbol, sign, money, Marxian monetary theory, contemporary capitalism

\section{JEL Classification}

B51, P16

+ Este trabalho faz parte de uma pesquisa mais ampla, financiada por bolsa de produtividade em pesquisa do CNPq da primeira autora e foi desenvolvido no âmbito das atividades do Cafin, grupo de pesquisa Instituições do Capitalismo Financeiro, registrado na mesma instituição. Os autores agradecem os comentários e sugestões de dois pareceristas anônimos da REE.

* Departamento de Economia, Faculdade de Economia, Administração e Contabilidade, USP ( FEA/USP) e Pós-Graduação em Economia (IPE/USP). E-mail: paulani@usp.br.

** Departamento de Filosofia, Faculdade de Filosofia Letras e Ciências Humanas, USP (FFLCH/USP) e FAPESP. E-mail: lapmuller@gmail.com.

Endereço para contato: Departamento de Economia, FEA-USP - Av. Prof. Luciano Gualberto, 908, Edifício FEA II, $1^{\circ}$ andar. CEP: 05508-900.

(Recebido em abril de 2009. Aceito para publicação em junho de 2010). 


\section{Introdução}

O objetivo deste artigo é levantar alguns aspectos sobre a questão do dinheiro no capitalismo contemporâneo a partir de um enfoque marxista para demonstrar o ineditismo da presente fase histórica. Dado que, para Marx, para o papel de dinheiro mundial "sempre é exigida a mercadoria monetária efetiva, o ouro e a prata em pessoa" (MARX, 1984, p. 120), a questão que se coloca é a seguinte: como pode uma mera moeda - o uniforme nacional do dinheiro - se colocar como o dinheiro mundial? Em outros termos, como pode o dólar americano ser medida do valor, meio de circulação, tesouro e meio de pagamento em nível mundial? Tal situação não estava dentre as possibilidades vislumbradas por Marx. No entanto, aí está a realidade, alargando o campo destas.

Para uma adequada colocação do problema, faremos uso de um desvio epistemológico, desvio exigido pela natureza contraditória do objeto e pela forma de abordá-lo que está implícita na análise marxiana. Assim procedendo, resvalaremos inevitavelmente no domínio filosófico, apesar de a questão pertencer, sem sombra de dúvida, ao domínio econômico. ${ }^{l} \mathrm{O}$ resgate da dialética permitirá demonstrar, assim esperamos, a novidade que instaura a atual fase do desenvolvimento capitalista, isto é, ressaltar a diferença que confere ao capitalismo contemporâneo seu caráter inédito. Para tanto, uma incursão nos densos textos hegelianos é incontornável. ${ }^{2}$ Iremos buscar ali a estruturação do ato que põe o homem como sujeito a partir dos campos simétricos da linguagem e do trabalho, estruturação que se dá através da exteriorização do ser do homem (segunda seção). Tal exteriorização segue, grosso modo, dois paradigmas, que são anteriormente apresentados, quais sejam, o símbolo e o signo, sendo este último o elemento a partir do qual o pensamento especulativo pode se estabelecer (primeira seção). Na terceira seção, buscamos demonstrar como Marx, pensando dentro do arcabouço hegeliano, articula a "linguagem das mercadorias", ou seja, a capacidade que os produtos do trabalho passam a ter de desenvolver uma "linguagem" (terceira seção). Tal problemática se articula em torno da questão do aparecimento do valor - de sua expressão - aparecimento que se cristaliza no dinheiro, o que recoloca o problema em um novo patamar (quarta seção), a partir do qual será retomada a questão da autonomia dos signos ante as coisas que representam (quinta seção) e a posição do dinheiro contemporâneo nesse processo.

1 Para uma discussão stricto sensu econômica, mas ainda dentro do arcabouço marxiano, o leitor interessado pode consultar Moseley (2005), uma alentada coletânea de textos sobre essa questão. Bonefeld e Holloway (1995) é outra opção, ainda que não tão focada. Em Smithin (2000), temos um conjunto de textos no campo da heterodoxia econômica, bastante direcionado à mesma questão, ainda que não restrito ao âmbito da teoria de Marx.

2 Por não se inserir no escopo do trabalho, não problematizaremos aqui - ao menos não diretamente - a complicada relação entre as dialéticas hegeliana e marxiana. Assumimos, no entanto, de maneira explícita, como se percebe, o hegelianismo de Marx. Em nosso entender, Fausto (1987) resolve a questão. 


\section{A Representação: Símbolo e Signo}

O que Hegel compreende por representação (Vorstellung) é fundamentalmente o pensar do "Entendimento", um pensar próprio à Modernidade. ${ }^{3}$ Entender algo consiste exatamente em categorizar o diverso da experiência a partir de predicados gerais, os quais se colocam como naturalmente dados e arbitrariamente justapostos. Para Hegel, então, a representação deve ser tal que seja "propriedade imediata do Si", ou seja, que se constitua como o Entendimento do sujeito. Em outras palavras, a representação deve ser constituída de modo a que o sujeito possa dispor dela como bem entender. Por um lado, re-presentar (vorstellen) - no sentido de (dis) por-diante-de-si (vor-sich-stellen $)^{4}$ - conforma, fundamentalmente, uma estrutura de reflexão posicional: o conteúdo da reflexão é posto diante do sujeito no interior da reflexão, como se colocássemos algo diante de um "olho da mente". Por outro lado, representação é a tomada de posse de algo pelo Si: todo ato de pensar é um ato de dominar através da submissão da coisa à representação.

A partir desse momento, o ente é aquilo que aparece para o sujeito cognoscente como objeto adequado de uma representação categorizada, isto é, articulada em coordenadas espaço-temporais precisas. Desse modo, algo só pode ser representado ao ser disposto dentro de um quadro ordenado. O problema é que este "entendimento tabelador" desconhece "o que constitui o concreto, a efetividade e o movimento vivo da Coisa que classifica. (...) tal procedimento só fornece uma indicação do conteúdo (Inhltanzeigen), e não o conteúdo mesmo" (HEGEL, 1952, p. 44; 2002, §53). Daí a acusação de exterioridade de tal conhecimento por parte do filósofo: exatamente por ser abstrato ele pertence ao sujeito; melhor, ele é a própria projeção do sujeito no objeto.

Apesar destas críticas ao Entendimento, Hegel não está disposto a abandonar o solo de uma filosofia da reflexão em prol de uma imanência pré-reflexiva e préconceitual - denominada de natureza -, a partir da qual o subjetivo e o objetivo se extrairiam. Não será recorrendo a intuições advindas deste plano de imanência que superaremos tais cisões provocadas pelo pensar representativo. Neste ponto,

3 Evidentemente não é este o local para que se empreenda a necessária discussão sobre o significado do termo "Modernidade", não por acaso grafado com a inicial em maiúscula. Para nossos propósitos, basta considerar que pode ser assim chamada a sociedade que começa a se formar no Ocidente a partir do século XV, marcada, de um lado, pela afirmação do capitalismo como forma de organização de sua reprodução material e, de outro, pelo desenvolvimento da Ciência passando pelo Iluminismo - como seu discurso por excelência (daí também porque a grafia com a inicial em maiúscula do termo "Entendimento", característico do universo de Hegel). Remetemos o leitor interessado nessa questão a Habermas (2000) e Paulani (2005).

4 Deleuze, a partir do idioma francês, lembra que "o que conta na representação é o prefixo: representação implica uma retomada ativa daquilo que se apresenta, (...) É a própria re-presentação que se define como conhecimento, isto é, como a síntese do que se apresenta" (2000, p. 16, grifo nosso). 
a crítica hegeliana tem como alvo o local privilegiado de aparição desta intuição: o símbolo.

Nos Cursos de Estética de Hegel encontramos sua definição de símbolo:

O símbolo em geral é uma existência exterior imediatamente presente ou dada para a intuição, a qual, porém, não deve ser tomada do modo como se apresenta de imediato, por causa dela mesma, mas deve ser compreendida num sentido mais amplo e mais universal. Por isso, devem ser distinguidas a seguir duas coisas no símbolo: primeiro o significado e depois a expressão do significado. Aquele [o significado] é uma representação de um objeto [já sujeita, portanto, à projeção subjetiva] (...), esta [a expressão] é uma existência sensível ou uma imagem de qualquer espécie [ainda autônoma frente ao sujeito]. (2000, p. 26).

Já podemos notar que o símbolo é o portador de uma ambiguidade: ele opera, de um lado, a representação subjetiva e, de outro, uma imagem ainda vinculada à existência imediata do objeto. O sentido preciso dessa definição fica mais claro quando o comparamos às observações de Hegel sobre o signo. Neste último, "a conexão que possui o significado e sua expressão (...) é apenas uma junção inteiramente arbitrária" (ibidem). O que indica que os signos propriamente ditos fecham-se num campo autônomo ante as coisas que designam, um campo que tem regras e lógica própria. ${ }^{5}$ Daí a arbitrariedade da conexão: "O signo (Zeichen) é uma intuição imediata, mas que representa um conteúdo absolutamente distinto daquele que a intuição [do objeto] tem para si” (HEGEL, 1995, §458). Apesar de, também no caso do signo, Hegel falar em "intuição imediata", o que é preciso reter de sua colocação é justamente a observação quanto "ao conteúdo absolutamente distinto daquele que a intuição tem para si". A esse respeito, é absolutamente pertinente a observação de Safatle: "Estranha 'intuição imediata' esta posta pelo signo já que é uma intuição que conserva a distância entre o conteúdo intuído e o conteúdo representado, entre o que é visado (Meinung) e o que é efetivamente dito" (2006, p. 112), e poderíamos completar entre o significado e a expressão e, em última instância, entre a coisa e a palavra.

O signo, portanto, trabalha sobre um fundo de distância, que está muito menos presente no caso do símbolo. Daí ser o signo a figura adequada à representação que, como vimos, trabalha como uma reflexão posicional - como o (dis)por diante de um olho da mente. Contra a arbitrariedade do signo, Hegel contrapõe inicialmente

5 Como se sabe, na direção contrária à do filosófo da Modernidade, as visões pós-modernas, em particular o Desconstrucionismo de Derrida e Lyotard, exacerbam esse poder autônomo dos signos para diminuir o poder da Razão e embaralhar os diferentes discursos. 
o caráter motivado do símbolo, no qual o conteúdo da intuição é apresentado de uma forma menos arbitrária, exatamente porque a expressão é ainda uma imagem do objeto designado. Entretanto, esta adequação entre expressão e significado do símbolo não é perfeita. Sua correta significação depende de uma convenção partilhada, de um contexto determinado: a atribuição simbólica articula o significado com apenas um dos muitos atributos da coisa sensível ou imagem que é utilizada como símbolo.

Na realidade, "o símbolo é o caso mais visível de um problema geral denunciado pela filosofia hegeliana: a impossibilidade de fundar o sentido através da pressuposição de imediatidade de uma referência naturalizada. A experiência imediata não possui a unidade de um domínio autônomo" (SAFATLE, 2006, p. 112), o que, por sua vez, as representações e seus signos têm. No símbolo, o apelo à referência é sempre indeterminado, pois a "quantidade de configurações e formações" simbólicas é "completamente infinita", ou seja, ela sempre desliza através do mau infinito da multiplicidade de perspectivas possíveis de apreensão: a cada angulação de meu olhar, o símbolo poderá fazer referência a um conteúdo diferente da angulação anterior. ${ }^{6}$ Por isso a linguagem simbólica pressupõe um texto anterior a ela, que permita escapar deste deslizamento: "a imagem sensível do triângulo em uma igreja cristã, por exemplo, pressupõe a existência de um texto escondido que nos permite passar do triângulo à trindade" (idem, p. 113). Daí porque o "símbolo permanece essencialmente ambíguo quanto ao seu próprio conceito” (idem, p. 28).

Hegel, portanto, não pode recorrer às intuições advindas de uma imanência préreflexiva e pré-conceitual, que tem no símbolo seu elemento por excelência. Tampouco pode contentar-se com uma filosofia da representação, cujo elemento privilegiado é o signo, exatamente devido à arbitrariedade deste. É verdade que este primado do signo fundará a Modernidade (esse momento em que a autonomização das representações ante as coisas pôde, pela primeira vez, se colocar plenamente), mas é para além dos signos e do pensar representativo que a dialética hegeliana nos levará.

6 Alguns exemplos talvez nos ajudem: tomemos o leão como símbolo da coragem. No entanto, a coragem é apenas um de seus múltiplos atributos; ele é também forte, esguio, altivo, etc., podendo, portanto, ser o símbolo de quaisquer destas características. Mesmo se focarmos em apenas um destes atributos, ele pode mudar de significado conforme o contexto: a astuta raposa pode ser símbolo da astúcia no sentido da inteligência; pode também ser o símbolo da astúcia no sentido da rapinagem. Um último exemplo: a suástica adquiriu, no século $\mathrm{XX}$, devido ao contexto em que foi utilizada (o nazismo), uma significação completamente distinta daquelas que possuía anteriormente em qualquer das inúmeras tradições (hinduísta, budista, grega, romana, celta, etc.) que a utilizaram. 


\section{A Ação Humana: Linguagem e Trabalho}

Hegel não poupa palavras ao criticar a fixidez e arbitrariedade próprias às representações. No entanto, numa aparente reviravolta, ele apontará que esta mesma força - qual seja, o Entendimento -, que produzia cisões aparentemente irreparáveis, era a "força maior e mais maravilhosa, ou melhor a potência absoluta." (HEGEL, 1952, p. 29-30; 2002 §32). Como explicar tal reviravolta?

Digamos, num primeiro momento, que o Entendimento, ao "dividir" o concreto tendo em vista a construção de seu quadro conceitual, é a única força capaz de retirar o sujeito da aderência ao imediato e das relações nas quais o sentido aparece como positividade oferecida a uma intuição imediata. Ou seja, o Entendimento é uma ruptura com o imediato e, exatamente por isso, pode ser o início do saber. ${ }^{7}$

No entanto, o conhecimento não pode ser reduzido a esse pensar da representação, a um conhecimento por signos. Hegel procura uma gramática que seja capaz de superar essa cisão engendrada pelo Entendimento. E ela será buscada na ideia de uma unidade negativa:

Mas o fato de que, separado de seu contorno, o acidental como tal - o que está vinculado, o que só é efetivo em sua conexão com outra coisa - ganhe um ser-aí próprio e uma liberdade à parte, eis aí a força portentosa do negativo: é a energia do pensar, do puro Eu. (HEGEL, 1952, p. 29; 2002, §32).

Traduzamos tal afirmação: o Entendimento, ao categorizar os entes num quadro ordenado, produz uma cisão no interior do próprio objeto. O ente é apreendido pelo sujeito enquanto é representável, enquanto se submete ao quadro conceitual imposto pelo sujeito. Entretanto, o que não acede à representação não é simplesmente expulso do campo da experiência do sujeito. Este resto - o "acidental como tal" subsiste e aparece como algo que não se deixa submeter à forma da representação e que, por isso, "ganha uma liberdade à parte". Eis então que a "energia do pensar" engendra não apenas um quadro onde os objetos são categorizados, mas também leva o sujeito a se confrontar com aquilo que só aparece sob "a força portentosa do negativo" (do que não é representável).

Uma correção ao nosso vocabulário se impõe aqui. Até agora utilizamos o termo "sujeito" como aquilo que se contrapõe a um objeto. No entanto, sujeito é, para Hegel,

7 Safatle (2006) aponta que "no parágrafo em questão da Enciclopédia, Hegel parece mais interessado na atividade criadora dos signos. Atividade que consiste em negar o imediato da intuição sensível a fim de possibilitar a produção de um 'outro conteúdo como significação e alma'." (p. 113). 
o nome daquilo que é capaz de internalizar esta negação advinda do próprio objeto e conservar-se enquanto tal. A verdadeira subjetividade não apenas internaliza este negativo, mas transforma-o em ser, dota-o de determinação objetiva. No entanto, tal tarefa só poderá ser cumprida se o campo da representação for abandonado (já que "o resto" não acede à representação). Mas, como já vimos, esse abandono não consiste numa volta ao primado do imediato, um retorno a um saber simbólico, mas a procura por um modo de conceitualizar que não se dê através de representações. ${ }^{8}$ Eis o ponto nevrálgico da filosofia hegeliana: "Trata-se do mesmo poder que acima se denominou sujeito, e que ao dar, em seu elemento, ser-aí à determinidade, suprime (aufhebt) a imediatez abstrata, quer dizer, a imediatez que é apenas ente em geral.” (HEGEL, 1952, p. 29; 2002, §32). O sujeito hegeliano é fundamentalmente o nome desta negação que não se deixa objetivar sob a forma da representação. Uma negatividade que é experimentada pela consciência em toda tentativa de apreensão do mundo a partir do pensar representativo. ${ }^{9}$

Subjetividade, por sua vez, implica necessariamente ação. ${ }^{10}$ E será nesta que Hegel fundará o ser do homem: "O verdadeiro ser do homem é, antes, o seu ato (...). O ato é isto; e seu ser não é somente um signo, mas a Coisa mesma. O ato é isto, e o homem individual é o que o ato é” (idem, 1952, p. 236; 2002, §322). A passagem não poderia ser mais clara: o homem é aquilo que faz, é enquanto subjetiva-se. Pois, é no fazer que o homem traz à tona aquilo que se aloja na interioridade da intencionalidade: o ato é a exteriorização mesma da intenção. Tal colocação é central e traz com ela a seguinte: "Linguagem e trabalho são exteriorizações (Außerungen) nas quais o indivíduo não se conserva nem se possui mais em si mesmo; senão nestas

8 É preciso compreender bem o sentido que tem aqui o termo "abandono", pois não se trata de, pura e simplesmente, deixar de lado o pensar representativo, mas sim de operar para além dele, exatamente a partir do resto que ele produz - o "acidental" da citação acima. Isso explica a apresentação do entendimento como "a potência absoluta": ele abre um novo campo ao saber ou, mais corretamente, ele permite ao saber se desdobrar num círculo mais alto (e, para Hegel, absoluto). Esse abandono é, portanto, um abandono que conserva, pois não é possível chegar ao absoluto a não ser passando pelo e superando o pensar representativo.

9 Note-se que, grosso modo, este é o mesmo procedimento utilizado por Marx, já operando no quadrante materialista: mercadoria e dinheiro são representações. No entanto, é a partir do "resto" delas que ele compreende o sujeito capital: ele não é mercadoria, nem dinheiro, ele é o movimento incessante de passagem deles um no outro (D-M-D'), ou seja, o capital é exatamente aquilo que não se deixa representar, aparece como um negativo e, por isso, ganha uma liberdade à parte e pode se colocar como sujeito.

10 São inúmeras as passagens na obra de Hegel que apontam neste sentido. Na Fenomenologia lemos que "a substância viva é o ser, que na verdade é sujeito, ou - o que significa o mesmo - que é na verdade efetivo, [mas] só na medida em que é o movimento do pôr-se-a-si-mesmo" (HEGEL, 1952, p. 20; 2002, §18). Na Enciclopédia, ao falar sobre o desejo, ele afirma que "O sujeito intui no objeto sua própria falta (Mangel), sua própria unilateralidade - ele vê no objeto algo que pertence à sua própria essência e que, no entanto, lhe falta. A consciência-de-si pode superar esta contradição por não ser um ser, mas uma atividade absoluta" (idem, 1995, §427, adendo). Na Filosofia do Direito: "O que é o sujeito, é a série de suas ações" (idem, 1986, v7 e 1998, §124). Quanto a Marx, vale lembrar a retomada feita por ele de Goethe: "Em sua perplexidade, pensam os nossos possuidores de mercadorias como Fausto. No começo era a ação. Eles já agiram, portanto, antes de terem pensado." (MARX, 1983, p. 80). 
exteriorizações faz o interior sair totalmente de si, e o abandona a Outro" (idem, 1952, p. 230; 2002, §312).

Aquilo que se alojava no interior do homem - seu ser mesmo -, através do agir deste, é exteriorizado. Mas não se trata de uma exteriorização qualquer: nela o indivíduo se perde em prol de um outro, se aliena. Mais, tal alienação deve ser a mais universal possível, deve ser infinita, absoluta. ${ }^{11}$ No que tange ao trabalho, a alienação é resultado da submissão da consciência escrava/serva ao senhor. Na luta por reconhecimento, ao temer a morte, o escravo aceitou se submeter ao senhor e por isso é obrigado a trabalhar. Trabalhando ele adequa a natureza ao desejo do senhor, mas, ao fazê-lo, está refreando, inibindo o seu desejo. ${ }^{12}$ Somente assim ele será capaz de estabilizar a essência fluida resultante do medo da morte, do serviço ao senhor absoluto, ${ }^{13}$ vale dizer, é somente assim que o sujeito será capaz de dar forma à indeterminação própria à experiência (produzida pelo operar do entendimento): "Esse meio termo negativo, ou agir formativo é, ao mesmo tempo a singularidade, ou o puro ser para si da consciência, que agora no trabalho se transfere para fora de si no elemento do permanecer" (idem, 1952, p. 148-9; 2002, §195). Assim, com o trabalho, aquilo que é próprio à subjetividade adquire uma figura estável no produto, exterioriza-se, objetiva-se e dá uma forma adequada à essência fluida (universal) que resultou do medo da morte - também porque o produto do trabalho transcende ao trabalhador e ao processo (ambos particulares) que o produziram. ${ }^{14}$

O mesmo movimento pode ser visto em operação na linguagem. Ao falar, o sujeito se exterioriza porque "o som [é] a exteriorização cabal da interioridade que se faz conhecer" (idem, 1995, §459). No entanto, à fala (que Hegel denomina de "língua original") falta o momento do permanecer, da subsistência: o som se esvanece no instante mesmo em que é pronunciado:

11 Exatamente porque o sujeito hegeliano busca validar suas ações universalmente, isto é, para além de todo e qualquer contexto determinado.

12 "O trabalho, ao contrário, é desejo inibido/refreado (gehemmte Begierde), um desvanecer contido, ou seja, o trabalho forma (bildet). A relação negativa para com o objeto torna-se a forma do mesmo e algo permanente (Bleibende), porque justamente o objeto tem independência para o trabalhador." (HEGEL, 1952, p. 148-9; 2002, §195).

$13 \mathrm{O}$ medo da morte é "uma angústia não por isso ou aquilo, não por este ou aquele instante, mas sim através de sua essência toda, pois [a consciência de si escrava] sentiu o medo da morte, do senhor absoluto. Aí se dissolveu interiormente; em si mesma tremeu em sua totalidade; e tudo que havia de fixo, nela vacilou." (HEGEL, 1952, p. 148; 2002, §194). Não devemos ler esta passagem a partir de um ponto de vista existencialista. A morte é simplesmente o operador fenomelógico da indeterminação: dizer que o escravo teme a morte é outra forma de dizer que o sujeito tem de lidar com aquilo que não acede à representação, com aquilo que não se deixa determinar. Encarar de frente esta indeterminação (temer a morte e implementá-la - a indeterminação através do trabalho) é a única via possível para a posição de um fundamento absoluto. Vide a nota anterior.

14 A este respeito Hegel afirmará na Filosofia do Direito: o dar forma (Formierung) é o movimento através do qual "a determinação de que algo é meu ganha uma exterioridade subsistente por si e deixa de ser limitada à minha presença neste espaço e neste tempo e à presença de meu saber e minha vontade." (1986, v.7, §56). 
O som que se articula mais para as representações determinadas, a palavra e seu sistema, a linguagem, dão às sensações, intuições, representações uma segunda existência (Dasein), superior à sua existência (Dasein) imediata [isto é, o som]; e uma existência (Existenz) que vigora no reino da representação. (ibidem)

Já a escrita alfabética é capaz de dar conta desta dupla exigência de alienação e universalidade. Em primeiro lugar, por transcender seu autor, um texto escrito supera a particularidade espaço-temporal da fala (os símbolos também são capazes disso); em segundo, exatamente por ser referência a esta "língua original" falada - isto é, por operar uma espécie de referência de segunda potência, por ser composta de "signos de signos (Zeichen der Zeichen)" (ibidem) - a escrita alfabética aparecerá, portanto, como o campo mais adequado (vis-à-vis à língua falada e a uma escrita simbólica) para a manifestação desta alienação infinita necessária à posição da verdadeira subjetividade:

a linguagem é a existência (Dasein) do puro Si (...). [Ela] contém o Eu em sua pureza; só expressa o Eu, ele mesmo. Essa sua existência é, enquanto existência, uma objetividade que contém nela a verdadeira natureza dele. Eu é este Eu [um singular] - mas [é] igualmente universal; seu aparecer também é imediatamente a exteriorização e o desaparecer deste Eu e, através disso, seu permanecer em sua universalidade. (idem, 1952, 2002, §508).

O resultado dessas exteriorizações (seja através do trabalho, seja através da linguagem) se concretizará na obra (Werk). Uma obra que permitirá a plena posição do sujeito tão logo o sujeito a compreenda como a formalização do descompasso entre a efetividade e o conceito, entre obra e intenção. Vale ressaltar, este caminho estará aberto apenas se o sujeito aceitar se perder por completo no resultado de sua ação, um resultado que, por ser externo a ele, está sujeito à ação alheia e é, portanto, também resultado deste agir alheio. ${ }^{15}$ Neste momento, o conteúdo dessa experiência será a própria obra evanescente (verschwindende Werk), onde "o que se mantém não é o desaparecimento, pois este é efetivo e vinculado à obra, desaparecendo com ela (isto é, o desaparecimento desaparece ele mesmo, o que aponta para a permanência da obra). O negativo vai ao fundamento junto com o positivo do

15 Num certo sentido, o que Hegel está dizendo é mais simples do que parece: para que eu possa me comunicar em português com alguém, é necessário que meu interlocutor partilhe do mesmo background linguístico (isto é, fale português); neste sentido, toda enunciação minha será também um agir dele. Ora, se associarmos a este background a exigência de universalidade, estaremos muito próximos do que Hegel compreende por espírito (e poderemos compreender nossa ação particular como imediatamente universal, exatamente por ser uma exteriorização deste espírito). No que concerne ao trabalho, o raciocínio é o mesmo: meu trabalho privado só terá validade se seu resultado for capaz de satisfazer uma carência social e, neste sentido, meu agir privado é agir de toda a sociedade. 
qual é negação (die Negative geht mit dem Positiven, dessen Negation es ist, selbst Grunde)" (HEGEL, 1952, p. 293; 2002, §408) e tal sujeito adquire o solo a partir do qual pode erguer-se. ${ }^{16}$

No entanto, aqui não é a formulação hegeliana em si mesma que nos interessa. O ponto a ressaltar é que a análise feita por Marx das formas do valor opera como que num espaço de conjunção dessas duas formas estruturalmente similares de exteriorização do homem. A energia do pensar, que produz a ruptura com o imediato e a cisão do concreto, empurra o sujeito a se reconhecer como aquilo que não se deixa dominar, como aquilo que não se deixa objetivar pelo pensar da representação. Mas o homem só é quando subjetiva-se, e subjetivar-se é agir. Seu ser, portanto, é a ação e o ser do ato "não é um signo, mas a Coisa mesma (Sache selbst)."17 Essa Coisa mesma, porém, só se põe exteriorizando-se (já que a intenção só põe o sujeito plenamente quando se nega como intenção e desvela em ação). É nos campos da linguagem e do trabalho que, de um lado, a subjetivação viola a intuição imediata e, de outro, susta a imediaticidade do desejo (a satisfação das necessidades). A alienação que assim se produz e que, em Hegel, abre espaço para a plena posição do sujeito/ espírito, ${ }^{18}$ na análise marxiana aparece como o primado da mercadoria. Assim, ao se pôr como mercadoria, o produto do trabalho, essa Coisa mesma produzida pela consciência astuta, que deveria permitir ao sujeito retornar a si mesmo de sua coisificação, faz o caminho contrário: se objetiva e se submete à representação. Daí porque é possível a Marx falar numa "linguagem das mercadorias".

\section{A Linguagem das Mercadorias}

Vimos que o signo não é a única forma de estabelecer uma relação entre palavra e coisa. Além do signo, entendido a partir do pensar representativo, Hegel compreendia o símbolo como uma outra forma, pré-moderna, de estabelecimento dessa

16 Hegel faz uso de um jogo de linguagem intraduzível para o português: zugrunde gehen significa destruir-se, aniquilar-se; zu Grunde gehen significa, literalmente, ir ao fundo. Hegel associa estes dois significados e compreende o momento de aniquilação da estrutura representativa do sujeito como a posição do fundamento do saber. Grosso modo, o momento em que o "resto" não pode mais ser deixado de lado e vem ao centro, agora não mais como um "resto", mas como o próprio fundamento.

17 Coisa deve ser compreendida no sentido de assunto, de questão, e não num sentido de coisa material, tralha (Ding).

18 Vimos acima que não é qualquer alienação que levará a uma plena posição do sujeito: "Só mediante o pôr a vida em risco, a liberdade se conquista e se prova que a essência da consciência-de-si não é o ser, nem o modo imediato como ela surge, nem o seu submergir-se na expansão da vida, mas que nada há para a consciência que não seja para ela momento evanescente (verschwindendes Moment); que ela é somente puro ser-para-si. O indivíduo que não arriscou a vida pode ser bem reconhecido como pessoa (Person), mas não alcançou a verdade desse reconhecimento como uma consciência-de-si independente" (HEGEL, 1952, p.144; 2002, §187). 
ligação. ${ }^{19}$ Entre mercadoria e dinheiro ou, se se quiser, na questão do dinheiro como representante da riqueza material, encontra-se uma relação que, de início, está muito mais próxima da última que da primeira. É n'O Capital de Karl Marx que a questão é desenvolvida. Partindo da compreensão hegeliana do trabalho e da linguagem como processos simétricos de exteriorização do homem, ele compreendeu as relações entre os produtos do trabalho a partir de uma linguagem: a linguagem das mercadorias. Apesar de se mostrar como analogia, a referência à linguagem das mercadorias é operada por Marx, como tentaremos demonstrar, num sentido forte, que vai muito além do mero emprego de um recurso retórico.

A primeira, e mais explícita, passagem onde tal relação é demonstrada se encontra na análise da forma relativa da forma I da dialética do valor. Ali, Marx afirma que a mercadoria "revela seu pensamento em sua linguagem exclusiva, a linguagem das mercadorias" (MARX, 1983, p. 57). E, um pouco mais à frente, na seção sobre o fetichismo, apresenta outra característica desta linguagem, que é a posição de cada produto do trabalho como um hieróglifo social, elemento, como veremos, que traz, plasmadas em si, características do símbolo e do signo:

Ao equiparar seus produtos de diferentes espécies na troca, como valores, equiparam seus diferentes trabalhos como trabalho humano. Não o sabem, mas o fazem. Por isso, o valor não traz escrito em sua testa o que ele é. O valor transforma muito mais cada produto de trabalho em um hieróglifo social. Mais tarde, os homens procuram decifrar o sentido do hieróglifo, descobrir o segredo de seu próprio produto social, pois a determinação dos objetos de uso como valores é seu produto social, assim como a linguagem (Sprache). (idem, p. 72, grifo nosso).

Nos Cursos de Estética de Hegel, encontraremos o autor afirmando que "O Egito é a terra do símbolo" (HEGEL, 2000, p.77) e, mais à frente, lemos que

Num sentido semelhante, a escrita hieroglífica dos egípcios é também em grande parte simbólica, na medida em que ela procura dar a conhecer os significados por meio da reprodução de objetos efetivos, que não expõem a si mesmos, mas uma universalidade aparentada a ela, ou, de modo ainda mais frequente, no assim denominado elemento fonético desta escrita, ela indica as letras singulares por meio do desenho de um objeto, cuja letra

19 No âmbito do processo de representação, e na possibilidade que ele oferece de iniciar o saber (e realizar a razão), teríamos então, num crescendo, o seguinte esquema: a intuição imediata (o símbolo em sua ambiguidade), a representação (o signo em sua arbitrariedade) e o Conceito (capaz de apreender a Coisa mesma). 
inicial, em relação à língua, tem o mesmo som, o qual deve ser expresso. (idem, p. 81)

Se voltarmos à definição hegeliana de símbolo anteriormente referida, veremos que os hieróglifos são símbolos porque sua escrita (seu desenho) ainda faz referência direta ao objeto representado, ao mesmo tempo que, foneticamente, faz referência a uma sílaba que, junto com as outras sílabas representadas pelos hieróglifos ao redor, devem ser organizadas de maneira a revelar o verdadeiro significado. ${ }^{20}$ Nas palavras de uma egiptóloga: "[Os] hieróglifos (Hierogliphics), todavia, não eram somente um código (code) feito de signos abstratos arbitrariamente associados com significados linguísticos. ${ }^{21}$ Diferentemente dos signos sumários ou chineses, a escrita hieroglífica conservou sua natureza pictórica ao longo de toda sua história"22 (BETRÒ, 1996, p. 15). É exatamente esta natureza pictórica - a "expressão do significado" para retomarmos a terminologia hegeliana - que garante uma leitura imediata, ao mesmo tempo que esconde a leitura verdadeira, feita a partir das relações fonéticas - o "significado" ao qual o símbolo faz referência. O problema todo gira, pois, em torno desta dupla leitura possível, que também se verifica na relação entre valor e valor de troca, mostrando o caráter substantivo da analogia:

A relação valor-valor de troca cobre ela própria o campo, o conjunto do campo, do hieróglifo. Valor e valor de troca se relacionam como duas leituras possíves de um hieróglifo, uma leitura que remete à aparência, e uma leitura que remete à essência. Assim a comparação com o hieróglifo (...) serve (...) [exatamente] porque se trata de uma escrita críptica. (...) Os valores de troca sugerem um significado que é apenas aparente e que oculta o significado essencial. (FAUSTO, 1997, p. 82-83).

Assim, a partir da analogia com os hieróglifos, podemos perceber a profundidade da compreensão marxiana da relação entre valor e valor de troca:

20 "Mais precisamente, a escrita hieroglífica designa as representações por meio de figuras espaciais e, ao contrário, a escrita alfabética designa sons, que são eles mesmos sinais. Ela se compõe, portanto, de signos de signos, e de tal modo que dissocia os sinais concretos da língua falada, as palavras em seus elementos simples, e designa estes elementos.” (HEGEL, 1995, §459). Neste trecho vemos claramente que o hieróglifo já cindiu o imediato; no entanto, não se autonomizou dele, isto é, não se fechou por sobre si mesmo num campo autônomo ao objeto; sua referência ainda é direta ao objeto, ao contrário do que ocorre na escrita alfabética.

21 Seguindo a teoria hegeliana, diríamos que os hieróglifos não eram ainda um código feito de signos arbitrários.

22 A possibilidade desta dupla leitura foi efetivamente aproveitada pelos Faraós que fizeram dos hieróglifos as "manudecera", as "palavras divinas", de onde vem o termo grego "ierogluphikà" (BETRÒ, 1996, p. 14). 
No plano da analogia com o hieróglifo, a unidade está dada pela existência de um único significante (...), no plano real a unidade está dada no fato de que se trata da relação entre dois momentos da forma, a forma enquanto forma (valor), e a forma posta na matéria (valor de troca). A matéria está lá, mas como matéria da forma." (idem, p. 83).

Lembremos da relação entre as formas relativa e equivalente, que caracterizam a equação de troca: como bom hegeliano, para Marx, o valor somente será se aparecer - mais, tal aparecimento se dará somente através de uma passagem no oposto -, e isso somente ocorre na relação de troca. Ali, o valor de uso (a matéria) da mercadoria equivalente serve para expressar - funciona como um "espelho" - do valor da mercadoria relativa. ${ }^{23}$ Ora, o valor de uso da mercadoria equivalente funciona aqui apenas enquanto é apropriado pelo valor da mercadoria relativa - o sujeito da relação -, funciona apenas como matéria para a expressão do valor, não como um valor de uso em si mesmo. Assim, o casaco só vale enquanto casaco porque é enquanto casaco que ele pode funcionar como expressão do valor do linho. O casaco, portanto, não vale como casaco, mas vale por sua aparência de casaco, a qual pode, por isso, apresentar o essencial, o valor do linho. ${ }^{24}$ No caso do hieróglifo, a matéria - a imagem pictórica - vale apenas enquanto matéria que remete ao fonema, não em si mesma.

Voltando a Marx, a dupla leitura não somente é possível, como é real, tão real que:

A tardia descoberta científica, de que os produtos do trabalho humano, enquanto valores, são apenas expressões materiais do trabalho humano despendido em sua produção, faz época na história do desenvolvimento da humanidade, mas não dissipa, de modo algum, a aparência objetiva das características sociais do trabalho. O que somente vale para esta forma particular de produção (...) parece àqueles que estão presos às circunstâncias da produção mercantil, antes como depois dessa descoberta, tão

23 "O valor da mercadoria linho é assim expresso no corpo da mercadoria casaco, o valor de uma mercadoria no valor de uso de outra. Como valor de uso é o linho uma coisa sensivelmente diferente do casaco, como valor é algo igual ao casaco e parece, portanto, como um casaco. Assim o linho recebe uma forma de valor diferente de sua forma natural. Sua existência de valor aparece em sua igualdade com o casaco." (MARX, 1983, p. 57). Note-se o processo de apropriação do natural - o valor de uso - pelo social - o valor, ou seja, que o social só pode aparecer enquanto natureza: eis a produção de "outro conteúdo [social] como significação e alma" do objeto natural (ver nota 7).

24 Não é necessário lembrar que a base deste processo é a apropriação, pelo valor da mercadoria relativa, do trabalho concreto da mercadoria equivalente, enquanto representante do trabalho humano abstrato. Bastaria lembrar das três "peculiaridades" da forma equivalente indicadas por Marx, para notarmos que é do fetichismo que se trata aqui. 
definitivo quanto a decomposição científica do ar em seus elementos deixa perdurar a forma do ar, enquanto forma de corpo físico. (MARX, 1983, p. 74).

\section{O Dinheiro}

Ora, se, como vimos acima, tal problemática está intimamente relacionada com a questão do aparecimento do valor, ${ }^{25}$ não nos surpreenderemos de reencontrá-la na análise marxiana do dinheiro. E ela aparece por ocasião da posição do dinheiro enquanto medida do valor e, necessariamente, padrão dos preços:

A denominação de uma coisa é totalmente extrínseca à sua natureza. Eu não sei nada de um homem sabendo que o seu nome é Jacobus. Do mesmo modo desaparece nos nomes monetários libra, táler, franco, ducado etc. qualquer vestígio da relação de valor. A confusão sobre o sentido secreto deste signos cabalísticos (kabbalistischen Zeichen) é tanto maior na medida em que as denominações monetárias expressam ao mesmo tempo o valor das mercadorias e partes alíquotas de um peso metálico, do padrão monetário. (MARX, 1983, p. 91, grifo nosso).

O problema central da cabala - ao menos no que nos concerne aqui - pode ser colocado nos termos do misticismo em geral: "Um místico é um homem que foi favorecido por uma experiência imediata, e, para ele, real, do divino, da realidade última, ou que pelo menos esforça-se para conseguir uma tal experiência." (SCHOLEM, 1988, p. 12).

Ora, quanto mais intensa e profundamente é experimentado o contato com Deus, tanto menos é ele suscetível de definição objetiva, pois por sua própria natureza transcende as categorias de sujeito e objeto. (...) Mas se tenta comunicar sua experiência - e é somente assim procedendo que ele se nos dá a conhecer - é obrigado a interpretá-la por meio de linguagens, imagens e conceitos previamente existentes. (idem, p. 15).

A questão assume outra dimensão quando se trata de (re)interpretar um texto sagrado: "o texto sagrado é escorificado e descobre-se nele um novo significado. Em outras palavras: o texto sagrado perde sua forma e, para o místico, adquire uma

25 Mais do que simplesmente afirmar que o aparecimento do valor põe esta problemática, tal problemática é o próprio aparecimento do valor. 
nova. A questão do significado torna-se suprema” (idem, p. 19). Em suma, o místico "considera o significado literal como simplesmente não existente, ou válido por um espaço de tempo limitado. O significado literal é substituído por uma interpretação mística” (idem, p. 22).

No caso do misticismo judaico, a situação é mais mediada, pois seu impulso original sempre foi no sentido de uma "reação contra a mitologia" (SCHOLEM, 1988, p. 106). Em oposição às religiões panteístas e mitológicas, "o judaismo visava a uma separação radical desses três domínios [Deus, cosmo e homem]; e, acima de tudo, considerou fundamentalmente intransponível o abismo entre o Criador e Sua criatura. (...) Os filósofos e teólogos estavam preocupados, antes e acima de tudo, com a pureza do conceito de Deus" (idem, p. 106-107). Em nossos termos, portanto, a letra da Torá despojava-se de todo simbolismo para colocar-se enquanto puro signo.

Quando, em fins do século XII, no Languedoc, surgiram os primeiro cabalistas (SCHOLEM, 1988, p. 28), sua tarefa consistia exatamente em re-simbolizar a letra hermética da tradição rabínica, com o intuito de revivificar esta escrita pura (idem, p. 106-109). Mas como isso era possível? Sabemos que, na cabala, as letras do alfabeto hebraico também representam algarismos. Ora, "se as letras correspondem a algarismos, as palavras indicam números, mas a estes correspondem significados que não são os significados usuais de cada palavra." ${ }^{26}$ (FAUSTO, 1997, p. 100). Temos aqui, então, nos signos cabalísticos a que se refere Marx, como que a potencialização da cifra introduzida pela relação do valor com o valor de troca: "O hebraico redobra de certo modo o hieróglifo, que representa a primeira cifragem. O código cabalístico cifra o que já era uma cifra" (idem, ibidem). Daí porque, de certo modo, "a decifração do segundo código só nos conduz à forma do valor, que é ela mesma cifrada. (...) Expresso pelo estalão de preços, o dinheiro se transforma (...) em dinheiro de conta (Rechengeld), dinheiro de cálculo" (idem, p. 99-100). Assim, se a forma equivalente que expressa o valor da forma relativa já é uma cifra, o caráter impositivo que tem a posição dessa expressão num estalão (sem o que não se põe a medida do valor, pois a expressão indicaria então apenas valor em geral, não valor determinado, grandeza de valor) cifra o que já estava cifrado. Assim a constituição do dinheiro de conta

26 Numa bela metáfora, os cabalistas consideram as palavras da Torá qual uma noz: "Como é que se entende isso? Do mesmo modo que uma noz tem uma casca e um cerne, assim cada palavra da Torá contém um fato externo (maassé), [um] midrasch, [um] hagadá, e [um] mistério (sod), cada um dos quais possui um significado mais profundo que o anterior." (SCHOLEM, ibid., p. $68)$. 
(que torna efetiva a posição do dinheiro como medida do valor) como que eleva ao quadrado a ilusão ${ }^{27}$ já presente na relação entre valor e valor de troca. ${ }^{28}$

Daí o nominalismo extremado de Marx na citação que abre esta seção, nominalismo que expressa um formalismo vazio de conteúdo, expressão que toma a forma do cálculo. ${ }^{29} \mathrm{E}$, se é verdade, como nos aponta Fausto, que "o cálculo é a linguagem por excelência do Entendimento" (FAUSTO, 1997, p. 100), a colocação de Marx ganha ainda mais determinações, as quais, no entanto, não cabe aqui analisar. ${ }^{30}$ Passemos então à próxima figura do dinheiro, qual seja, aquela que aparece quando ele se põe como meio de circulação, pois é nela que veremos mais explicitamente a passagem do símbolo ao signo. Como Marx deixa claro, nessa figura o ouro pode ser substituído por papel-moeda:

O conteúdo metálico das senhas de prata e de cobre é determinado de forma arbitrária pela lei. $\mathrm{Na}$ circulação elas se desgastam ainda mais rapidamente que as moedas de ouro. E, portanto, sua função monetária torna-se, de fato, totalmente independente de seu peso, isto é, de todo o valor. A existência do ouro como moeda dissociase radicalmente de sua substância de valor. Coisas relativamente sem valor, bilhetes de papel, podem, portanto, funcionar em seu lugar, como moeda. (MARX, 1983, p. 108).

E mais à frente:

A moeda papel é o signo do ouro ou signo de dinheiro. Sua relação com os valores mercantis consiste apenas em que estes estão expressos idealmente nas mesmas quantidades de ouro que são representadas simbólica e sensivelmente pelo papel. Somente na medida em que representa quantidades de ouro, que são também, como todas as quantidades de mercadorias, quantidades de valor, a moeda papel é signo de valor. (idem, p. 109).

27 O termo ilusão está sendo utilizado aqui não no sentido usual, de ilusão subjetivamente constituída, decorrente de um engano de percepção, mas no sentido de ilusão objetiva, ilusão que é sistemicamente construída, pois, se o velamento das relações sociais que a produz deixar de existir, estaremos evidentemente em outro sistema social.

28 Note-se que a cabala apenas exarceba a relação fundamental da escrita alafabética, isto é, a relação a outro signo, e não diretamente ao objeto. Isso explica porque Marx utiliza o termo "signos cabalísticos" e não "símbolos cabalísticos" ao traçar sua analogia.

29 "O cálculo é a expressão vazia do formalismo em que o conteúdo se esvai." (FAUSTO, p. 100).

30 Basta lembrar como, nas reflexões maduras de Marx, o pensar do Entendimento aparece muitas vezes quase como sinônimo de ideologia. Voltando a Hegel, se lembrarmos que o Entendimento trabalha a partir de representações e é a base da ciência moderna temos outro problema montado. 
E ainda:

Reflexo objetivado evanescente dos preços das mercadorias [o dinheiro] funciona apenas como signo de si mesmo e, por isso, pode ser substituído por outros signos. O signo do dinheiro só necessita de sua validade social objetiva própria e esta é recebida pelo símbolo de papel mediante o curso forçado. (idem, p. 110).

Vemos aqui, de maneira sintética, como Marx atualiza em sua teoria monetária a distinção hegeliana entre símbolo e signo. Generalizando, a moeda papel é signo do valor de troca porque a forma que o dinheiro de papel tem já está completamente distanciada da forma mercadoria (o que não ocorre com as moedas metálicas, nelas o ouro funciona como símbolo). ${ }^{31}$ Vale dizer, o "valor" inscrito nas moedas de papel não tem relação alguma com seu peso. Mas, justamente por serem signos, sem a designação explícita de que representam o ouro (designação que estava presente nas notas de dólares americanos até 1971), tais notas não podem mais simbolizar o valor. ${ }^{32}$ Sua relação é tal qual a da escrita alfabética ante a "língua original" do valor de troca. Por isso mesmo, as possibilidades de expressão do sujeito capital se veem potencializadas: enquanto o dinheiro é uma mercadoria plena (tal qual o ouro), o capital se vê constrangido pela matéria natural que lhe serve de suporte; quando o dinheiro deixa de ser uma mercadoria plena, sua expressão ganha a liberdade necessária para sua plena posição enquanto o sujeito que ele é (um sujeito automático e cego, é verdade, mas ainda assim um sujeito). ${ }^{33}$

A substituição de peças metálicas por papel moeda é, nos limites da circulação nacional, uma possibilidade real. ${ }^{34}$ Substituição possível na medida em que a função do dinheiro como meio circulante é isolada e tornada autônoma. Nos limites d'O Capital, ressaltemos, essa possibilidade só é aberta às peças de ouro realmente em

31 O ouro opera tal qual a escrita hieroglífica porque porta uma ambiguidade: seu peso permite uma leitura imediata (o próprio peso) ao lado da leitura "correta" (o valor); já a moeda papel acaba com tal ambiguidade: uma cédula representa apenas um quantum de valor, não mais um quantum de matéria. Neste momento, a única forma de manter a dupla leitura é apelar para um procedimento cabalístico: supor que cada unidade monetária faça referência a uma segunda série de significados (tal qual os algarismos na cabala, que duplicam a referência das letras hebraicas).

32 Da seção precedente, um ponto deve estar claro: não é apenas o ouro que simboliza o valor. Qualquer mercadoria que funcione como forma equivalente terá seu valor de uso como a matéria de expressão do valor da mercadoria na forma relativa e permitirá uma dupla leitura (num certo sentido, o fetichismo nada mais é que a possibilidade desta dupla leitura).

33 Não estaria aí o fundamento econômico da impressionante exposição debordiana do capitalismo contemporâneo como sociedade do espetáculo? Lembremos do primeiro parágrafo: "Toda a vida nas quais reinam as modernas condições de produção se apresenta como uma imensa acumulação de espetáculos. Tudo o que era vivido diretamente tornou-se uma representação." (DEBORD, 1997, p. 13, grifo nosso).

34 Lembrando que, na lógica hegeliana, a possibilidade real é o meio termo que opera a passagem da possibilidade abstrata para a necessidade. 
circulação - às moedas em sentido estrito, isto é, ao dinheiro enquanto meio de circulação propriamente dito. Essa massa mínima que

reside constantemente na esfera da circulação, funciona continuamente como meio circulante e existe, portanto, exclusivamente como portador dessa função. (...) A representação autônoma do valor de troca da mercadoria é, aqui [em M-D-M], apenas um momento efêmero. É substituída de imediato por outra mercadoria. Por isso, basta que o dinheiro exista apenas de forma simbólica num processo que o faz passar continuamente de mão em mão. Sua existência funcional absorve, por assim dizer, sua existência material. (MARX, 1983, p. 110)

Em outros termos, para Marx, apenas na função de meio circulante - apenas enquanto moeda - o dinheiro pode ser substituído por meros signos. Mesmo que esta operação não seja completada no momento da compra (função de meio de pagamento) a substituição somente é possível nas funções relacionadas à circulação de mercadorias - somente no circuito M-D-M, portanto. Em suas outras determinações - enquanto fim -, o dinheiro deve ter uma existência material efetiva, deve ser uma mercadoria propriamente dita.

\section{A Autonomia do Signo}

Em sua Dialética do Esclarecimento, Adorno e Horkheimer apresentam o símbolo da seguinte forma: "A doutrina dos sacerdotes era simbólica no sentido de que nela coincidiam o signo e a imagem. Como atestam os hieróglifos, a palavra exerceu originariamente também a função da imagem." (ADORNO; HORKHEIMER, 1985, p. 30).

E, logo à frente, afirmam: "A separação de signo e imagem é inevitável" (idem, p. 31). Eles pensam principalmente na divisão do trabalho intelectual, na qual "a nítida separação da ciência e da poesia, a divisão de trabalho já efetuada com sua ajuda estende-se à linguagem. [Por sua vez, é] enquanto signo que a palavra chega à ciência" (idem, ibidem). Neste longo processo, primeiramente

Os símbolos assumem a expressão do fetiche. A repetição da natureza, que é o seu significado, acaba sempre por se mostrar como permanência, por eles representada, da coerção social. O sentimento de horror materializado numa imagem sólida tornase o sinal da dominação consolidada dos privilegiados. Mas isso 
é o que os conceitos universais continuam a ser, mesmo quando se desfizeram de todo aspecto figurativo. A forma dedutiva da ciência reflete ainda a hierarquia e a coerção. (ADORNO; HORKHEIMER, 1985, p. 34, grifos nossos).

Vemos então que a supressão - em sentido hegeliano - da forma simbólica não altera a relação entre comunidade e dominação à qual ela, em última instância, faz referência. Apenas a esconde ainda mais, na medida em que autonomiza-se plenamente em relação à coisa representada. A substituição dos símbolos por conceitos, na ciência, não altera em nada o fato de esta ser dependente de uma divisão social do trabalho, divisão esta calcada na hierarquização e na dominação. ${ }^{35}$

Eis analogamente o que aconteceu com o dinheiro. Em lugar do ouro e daquilo que o simbolizou até há pouco tempo, ${ }^{36}$ temos atualmente - plenamente desde 1971, mas num processo que já vinha se desenvolvendo pelo menos desde $1930^{37}$ - um signo completamente autonomizado ante as coisas que representa: as mercadorias. ${ }^{38}$ A posição do dólar americano como dinheiro mundial apenas aumenta o grau de ilusão, ${ }^{39}$ exatamente na medida em que aumenta a distância entre significante e significado.

35 "É essa unidade de coletividade e dominação e não a universalidade social imediata, a solidariedade, que se sedimenta nas formas do pensamento." (ADORNO; HORKHEIMER, 1985, p. 35).

36 Talvez seja necessário esclarecer porque a moeda de ouro se põe diretamente como dinheiro, enquanto outros materiais não o fazem. Apesar de aparentemente simples, a pergunta não é fácil de responder. No âmbito do pensamento marxiano, a resposta é simplesmente que o ouro, ao ser objetivamente posto como equivalente geral, passou a representar diretamente a riqueza em geral, de modo que as moedas de ouro, independentemente de seu peso, ou, como diz Marx, "de todo o valor", põem-se como dinheiro e símbolo da riqueza. Mas essa pode, com razão, ser tida como uma resposta inteiramente teórica e, por isso, não suficiente. Nesse caso, teremos que lembrar que o ouro, para além, de suas propriedades materiais - durabilidade, divisibilidade, etc. - sempre deteve essa capacidade de representar a riqueza material, mesmo que desguarnecida do atributo abstrato que ela vem a ter no capitalismo. O fetiche do ouro é constituído justamente por isso: por se acreditar que o ouro concretamente (não em seu papel de dinheiro) é a própria riqueza. O pensamento mercantilista, em plena transição entre a auri sacra fames de que nos fala Weber (1987) e a sociedade moderna, moveu-se por esse parâmetro.

37 Na realidade, tal situação está contida em possibilidade já na forma mercadoria. Mas é necessário que a produção de mercadorias atinja um certo nível de desenvolvimento para que tal autonomização ante a matéria se torne efetividade. São necessários mais estudos nesta direção, mas, intuitivamente - e num plano puramente lógico -, diríamos que é a plena adequação entre forma e matéria imposta pelo fordismo (ver PAULANI, 2001) somada à progressiva apropriação da ciência pela grande indústria que abre espaço para esta posição do dólar como dinheiro mundial.

38 Não ignoramos a censura de Marx: "Podendo o dinheiro ser substituído, em certas funções, por meros signos, surgiu o outro erro, que ele seja mero signo" (1983, p. 83; ver também a discussão sobre "convencionalismo" como a ilusão oposta ao "fetichismo" em FAUSTO, 1983, p. 143-178; idem, 1997, p. 75-85). No entanto, cabe insistir aqui que uma coisa é afirmar que o dinheiro é um signo (o erro censurado por Marx), outra é afirmar que, num determinado momento de desenvolvimento do modo de produção capitalista, um signo assumiu a função de dinheiro mundial e daí desdobrar algumas consequências.

39 Veja nota 28. 
Retomando a questão de maneira sintética: o dinheiro só é dinheiro enquanto fim, nunca enquanto meio. Sua primeira posição se dá como equivalente geral, mercadoria geral, veículo de expressão do valor (medido) de todas as outras mercadorias. Essa primeira posição é imprescindível para que ele se coloque não ainda como dinheiro, mas como meio de circulação do valor, mera moeda. Esta primeira figura do dinheiro, a moeda (que supõe sua posição como medida e expressão do valor) terá que ser negada (suprimida, no sentido hegeliano), para que o dinheiro se ponha efetivamente e plenamente como dinheiro, não como "meio" de realização de outro sujeito, ou como diz Marx, mera "forma evanescente das mercadorias". É ao negar esta primeira figura, portanto, que o dinheiro se torna dinheiro. Ao se tornar dinheiro ele ganha a liberdade de se retirar da circulação, de negá-la. Ele a nega, em primeiro lugar, pondo-se em sua figura corporificada, absoluta, como tesouro (porque evidentemente ele então não circula). Ele a nega, em segundo lugar, ao permitir, colocando-se como meio de pagamento, que a circulação mercantil aconteça, apesar de sua ausência. Se, enquanto tesouro, ele é matéria absoluta, enquanto meio de pagamento, ele é forma pura. É nesta segunda figura, adequada ao dinheiro enquanto tal, que o dinheiro indica sua contradição constitutiva: em sua essência ele é uma forma pura, mas forma pura que tem que aparecer como o contrário disso, como a matéria absoluta, a mercadoria absoluta, o porto seguro do valor. E isso nos leva à seguinte questão: qual seria então a matéria mais adequada para a efetivação de tal contradição?

Ora, se o dinheiro é forma pura, sua matéria adequada é uma não matéria e isto já é perceptível em sua colocação como moeda (lembremos que é como moeda que o dinheiro pode ser substituído por signos). Diferentemente das mercadorias profanas, seu valor de uso não depende de seu corpo, seu valor de uso é ser um não valor de uso. Sua função social como que suprime em si mesma as características corpóreas da mercadoria que funciona como equivalente geral. ${ }^{40} \mathrm{E}$, é importante ressaltar, este processo é necessário. Já estava presente no século XIX, ainda circunscrito, entretanto, às economias nacionais. Daí ter Marx concluído que, no plano mundial, era preciso "o valor em pessoa", ou seja, o ouro. Poderíamos então parafrasear Marx para dirigir a ele a mesma

40 Alfred Sohn-Rethel expôs esta contradição de maneira bastante interessante: "A multiplicidade das matérias indica já por si, que nenhuma delas pode valer como aquela essencialmente apropriada para o dinheiro. (...) De fato, a inconveniência do material monetário respectivo é reconhecida de toda forma pelo próprio instituto emissor na promessa de substituir grátis cada peça monetária gasta por seu curso normal, substituí-la por uma outra de pleno peso. Portanto, um material do qual, a rigor, se deveria fazer o dinheiro, não pode existir na natureza. (...) Portanto, ele dever-se-ia classificar como mero conceito, puro conceito não empírico. Mas daí concluir que o material monetário existe só no pensamento, é tão absurdo, quanto procurar um modelo deste material na natureza. Dinheiro mental não pode existir." (1989, p. 60-61). 
observação que ele dirige a Aristóteles: "assim como Aristóteles não pôde enxergar o valor, ainda que visse suas determinações, porque ele não estava objetivamente posto na sociedade de sua época [ainda organizada materialmente em torno do trabalho escravo e não em torno do mercado - e do trabalho assalariado], também não pôde Marx perceber que a essência da aparência de mercadoria do dinheiro é, ela própria, puramente formal e não pôde perceber isso porque efetivamente a realidade do capitalismo do século XIX obrigava que o dinheiro se mostrasse como ouro" (PAULANI, 1991, p. 147).

Suas determinações (medida de valor, moeda, tesouro e meio de pagamentos) não se alteram quando ele passa a atuar no plano mundial. Entretanto, "é só no mercado mundial que o dinheiro funciona plenamente como mercadoria, cuja forma natural é, ao mesmo tempo, forma diretamente social de realização do trabalho humano em abstrato. Seu modo de existir ajusta-se ao seu conceito” (MARX, 1983, p. 119). Tal forma de existência adequada ao dinheiro não é, como pensava Marx - constrangido por um mundo dominado pelo padrão-ouro e pelo Bank Act de 1844 -, o ouro, mas sim esta forma pura que hoje vemos:

forma plástica que se materializa tanto num papel verde quanto num pedaço de poliéster magnetizado, tanto numa moeda metálica (ainda) quanto em impulsos elétricos que aparecem numa tela de computador quando uma transferência eletrônica é operada. ${ }^{41}$

Não nos enganemos, é exatamente este desprendimento total do dinheiro de uma 'mercadoria de verdade' também no âmbito mundial que permite realizar cabalmente a congruência entre meio e fim inscrita no movimento do capital financeiro. Prescindindo por definição da mediação efetuada pela mercadoria, a valorização financeira só encontra um ambiente adequado em nível mundial quando o próprio dinheiro mundial perde inteiramente seus vínculos com uma mercadoria de verdade. (PAULANI, 2005, p. 201-202).

41 O surpreendente não é que um signo possa desempenhar a função de dinheiro mundial, mas sim que Marx tenha restringido de tal forma sua análise. O ouro enquanto matéria monetária é claramente um empecilho para a plena posição do trabalho humano abstrato como substância do valor: enquanto uma mercadoria particular (ouro, prata, etc.), ocupa o lugar privilegiado de mercadoria monetária; sempre há a possibilidade real de que os trabalhos concretos e privados despendidos em sua produção (a mineração, a metalurgia, a ourivesaria, etc.) sejam postos como o próprio trabalho abstrato. 
Eis então que podemos voltar ao nosso ponto de partida: a Modernidade como o momento em que a autonomização das representações ante as coisas pôde, pela primeira vez, se colocar plenamente. Podemos completar - a partir do esquema hegeliano de compreensão da linguagem e do trabalho como processos simétricos de exteriorização e alienação dos sujeitos - que é somente agora que a Modernidade está caminhando sobre solo conhecido inclusive no plano material (econômico). Poderíamos mesmo arriscar a afirmação que finalmente entramos na Modernidade do capital. Mas, o que isso significa?

Significa, primeiramente, que o capital abandonou plenamente os últimos resquícios de sua aderência ao plano natural: ao ser o ouro - um símbolo - substituído por um mero signo também no plano mundial, o capital autonomiza-se de maneira total e completa. ${ }^{42}$ Póe-se, de maneira plena, como o sujeito automático e cego que é. Ora, isso nos indica que, finalmente, nos encontramos no auge do capitalismo. Capitalismo que sempre trouxe consigo uma combinação contraditória de progresso e barbárie, combinação esta que se faz - e, se a tese aqui apresentada tiver algum grau de correção, se fará cada vez mais - presente de maneira mais pura, e por isso mesmo, mais perversa.

Contraditoriamente, é exatamente o fetichismo da mercadoria a base de tal autonomização plena. Como mostra Marx, a posição do dinheiro como mercadoria, vale dizer, sua posição como capital portador de juros, é a última figura do fetiche, exatamente na medida em que ele toma para si, corporifica em si mesmo, o movimento de autovalorização. ${ }^{43} \mathrm{E}$ - a contradição jaz aqui - é exatamente este "corpo imaterial" que o dinheiro mundial - cujo "modo de existir ajusta-se ao seu conceito" (MARX, 1983, p. 119) - assume hoje que permite ao capital sua plena subjetivação. É somente nesta "matéria imaterial" que o fetiche se encontra em casa; é só ela que faz jus à forma que é a mercadoria.

42 Cabe aqui um esclarecimento. Evidentemente quando se faz referência à posição, também no plano mundial, de um dinheiro que é mero signo, não se quer com isso dizer que a função primeira (e primitiva) do dinheiro, qual seja a de fazer circular as mercadorias, tenha ganhado proeminência. Evidentemente o dinheiro mundial que é signo, e é essa a grande novidade, é o dinheiro de crédito, como o são hoje todas as moedas nacionais, e não o bilhete de papel que circula no lugar do ouro. Mas é preciso considerar também que, logicamente, é a posição do dinheiro como moeda, ou seja, a possibilidade que ela abre de o valor ser substituído por signos (ainda que restritos às funções que o dinheiro desempenha na circulação) que põe, por sua vez, a possibilidade de que um dinheiro de crédito (um signo que não seja mais representante explícito do valor) funcione como dinheiro pleno e, portanto, também como dinheiro mundial.

$43 \mathrm{O}$ desenvolvimento adequado desta questão pede um texto próprio. 


\section{Observações Finais}

Partiu-se aqui da leitura hegeliana, da qual Marx é tributário, para mostrar de que maneira, operada no quadrante materialista, a dupla exteriorização do homem na linguagem e no trabalho não resulta, como em Hegel, na plena posição do homem como sujeito, mas no desenvolvimento ao extremo da capacidade fetichista da mercadoria e do dinheiro, o que se configura, de certa forma, como sua antípoda. Como vimos, a alienação infinita exigida pelo processo de exteriorização do homem na linguagem impõe a constituição do conhecimento como conhecimento representativo (e não simbólico ou mitológico), ou seja, impõe a passagem da língua falada e da escrita simbólica para a linguagem alfabética escrita e sígnica, que é o instrumento primordial desse conhecimento. Simetricamente, no caso do trabalho, apesar da ruptura com o imediato que o processo de trabalho em si (qualquer processo de trabalho) implica, ela só se configura plenamente quando é o trabalho abstrato que comanda esse processo, ou seja, é só na sociedade moderna e capitalista que a alienação produzida pelo trabalho se torna de fato universal, infinita e absoluta, tal como exigida pelo processo de exteriorização. Um dos grandes feitos de Marx foi ter percebido a congruência e a confluência desses dois processos e ter podido, por isso, apreender a "linguagem das mercadorias". Mas tal alienação, como o próprio Marx demonstra, não é possível sem a cadeia de representações encarnada na sequência valor de troca, equivalente geral, moeda, dinheiro. Ora, também neste caso, o desenvolvimento histórico foi realizando aquilo que já estava inscrito em sua estruturação lógica: a posição de um dinheiro mundial (dinheiro pleno, portanto, não apenas meio de circulação) que é um puro signo, cujo significado é dado antes pela relação com outros signos dentro do sistema monetário mundial, do que por sua relação com qualquer mercadoria, tangível ou intangível, produzida pelo trabalho. Em outras palavras, hoje, um signo que não é mais representante explícito do valor (como o era o dólar americano até antes de 1971) funciona também como dinheiro mundial. Abre-se com isso o terreno para a posição plena da mercadoria capital, do capital portador de juros, última figura, e a mais alienada, mistificada e fetichista, segundo Marx, do próprio capital. Esse o ineditismo da fase atual e por isso afirmamos anteriormente que é somente agora que a Modernidade está caminhando em solo conhecido e que teríamos finalmente adentrado a Modernidade do Capital, pois é somente nesta matéria imaterial, que hoje ocupa o lugar do dinheiro, que o fetiche se encontra de fato em casa. 


\section{Referências}

ADORNO, T.; HORKHEIMER, M. Dialética do esclarecimento. Rio de Janeiro: Jorge Zahar, 1947-1985.

Temas básicos de sociologia. São Paulo: Cultrix, 1973.

SOHN-RETHEL, A. Geistige und körperliche Arbeit. Weinheim: VCH, 1989.

BETRÒ, M.C. Hieroglyphics - the writing of the ancient Egypt. New York: Abbeville Press, 1996.

BONEFELD, W.; HOLLOWAY, J. (Org.). Global capital, national state and the politics of money. Hampshire: Palgrave Macmillan, 1995.

DEBORD, G. A sociedade do espetáculo. Rio de Janeiro: Contraponto, 19671997.

DELEUZE, G. A filosofia crítica de Kant. Lisboa: Edições 70, 2000.

FAUSTO, R. Dialética marxista, dialética hegeliana: a produção capitalista como circulação simples. São Paulo: Brasiliense, 1997. (Oficina de Filosofia).

- Marx: lógica e política, investigações para a reconstituição do sentido da dialética. São Paulo: Brasiliense, 1983. tomo I.

Marx: lógica e política, investigações para a reconstituição do sentido da dialética. São Paulo: Brasiliense, 1987. tomo II.

Marx: lógica e política, investigações para a reconstituição do sentido da dialética. São Paulo: Editora 34, 2002. tomo III.

HABERMAS, J . O Discurso filosófico da modernidade. São Paulo: Martins Fontes, 2000.

HEGEL, G. W. F. Cursos de estética I, II, III e IV. São Paulo: Edusp, 1835-19992000-2002-2003.

_____ Fenomenologia do espírito. Petrópolis: Vozes, 1807-2002.

. Phaenomenologie des geist. Hamburg: Felix Meiner, 1807-1952.

. Enciclopédia das ciências filosóficas. São Paulo: Loyola, 1830-1995.

$3 \mathrm{v}$.

Werke in zwanzig Bändem. Organização de Eva Moldenhauer e Karls Markus Michel. Frankfurt am Main: Suhrkamp, 1986. Baseada na edição de 1832-1845.

MARX, K. O capital,. São Paulo: Abril Cultural, 1867-1983-1984. livro I, tomos 1 e 2. (Os economistas).

. O capital. São Paulo: Abril Cultural, 1885-1984. livro II. (Os economistas).

O capital,. São Paulo: Abril Cultural, 1894-1984-1985. livro III, tomos 1 e 2. (Os economistas). 
MOSELEY, F. (Org.). Marx's theory of money - modern appraisals. Hampshire: Palgrave Macmillan, 2005.

MÜLLER, Leonardo A. P. A Modernidade do capital. 2007. Monografia (Graduação em Economia) - FEA-USP, São Paulo, 2007.

PAULANI, L. M. Do conceito de dinheiro e do dinheiro como conceito. 1992. Tese (Doutorado em Teoria Econômica) - IPE/USP, São Paulo, 1992.

. O papel da força viva de trabalho no processo capitalista de produção - uma análise dos dilemas contemporâneos. Estudos Econômicos, São Paulo, v. 31, n. 4, 2001.

. Modernidade e discurso econômico. São Paulo: Boitempo, 2005.

SAFATLE, V . Linguagem e negação: sobre as relações entre ontologia e pragmática em Hegel. Dois Pontos, Curitiba, v. 3, n. 1, 2006.

SCHOLEM, G. A cabala e seu simbolismo. São Paulo: Perspectiva, 1988.

SMITHIN, J. (Org.). What is money. London: Routledge, 2000.

WEBER, M. A ética protestante e o espírito do capitalismo. São Paulo: Pioneira, 1920-1987. 